\title{
Última colonia penal insular de América Latina: Islas Marías, México (1905-2010)
}

Last insular penal colony in Latin America: Marias Islands, Mexico (1905-2010)

Evangelina Avilés

Universidad Autónoma de Sinaloa - México

Culiacán, México

eaviles@uas.edu.mx

\section{RESUMEN}

Poco se ha estudiado sobre las colonias penales insulares de América Latina, que datan de mediados del siglo XIX y XX. En este constructo, se estudia la última colonia penal insular, la Colonia Penal Federal Islas Marías, en México, que fue fundada en 1905 y cerró en 2010. Sin embargo, por la amplitud de sus 105 años de funcionamiento, solamente se estudia su proceso de fundación en 1905 y la justificación jurídica de la pena de relegación en 1908, que dio forma al modelo de colonia penal insular para operarla. El objetivo de la investigación es apoyar al conocimiento histórico de estas colonias penales insulares que, en su momento, sirvieron al quehacer del penitenciarismo de América Latina. Para la obtención de la información se aplica el método cualitativo y de investigación histórica. Los resultados obtenidos indican que en México, como en otras nuevas repúblicas de América Latina surgidas en el siglo XVIII, se retomaron los modelos europeos, y específicamente el modelo español del siglo XIX, para la creación de sus colonias penales insulares.

Palabras claves: Colonia penal insular; Código Penal; sistema penitenciario; América Latina; historiografía

\section{ABSTRACT}

There is a lack of studies about the insular penal colonies of Latin America, which date from the mid-19th and 20th centuries. This article studies the last insular penal colony, the Federal Penal Colony Islas Marias, in Mexico, founded in 1905 and closed in 2010. Due to the vast period of operation, 105 years, we only study two aspects: Its founding process (1905) and its legal justification for the penalty of relegation (1908), which gave shape to the model of insular penal colony to operate it. The objective of this research is to support the historical knowledge of these insular penal colonies that served for the work of the penitentiary in Latin America. The qualitative and historical research type method was applied. The results provide that in Mexico, like in other young Latin American republics from the 18th century, were replicated the European models, specifically the Spanish model of the 19th century, for the creation of their insular penal colonies.

Keywords: Insular penal colony; Penal Code; prison system; Latin America; historiography 


\section{INTRODUCCION}

Poco se conocen en el campo de las ciencias sociales y humanísticas en América Latina estudios sobre las extintas colonias penales insulares latinoamericanas. El objeto de estudio de este artículo está delimitado por la última de ellas, la Colonia Penal Federal Islas Marías, en México, creada en 1905 y cerrada en 2010. Esto genera recurrir a las siguientes preguntas conductoras de la investigación: ¿cómo se articularon en el pensamiento jurídico y penal para la creación de los modelos de colonias penales insulares en América Latina?; en términos de su justificación jurídica penal, ¿qué leyes la sustentaron?; y, por último, ¿cómo las operaron? Las respuestas tentativas son rescatadas, en principio, de los estudios de los códigos penales de los países de América Latina, ya que allí se señalan las directrices legales para sus creaciones.

Sin embargo, por la amplitud de operación de la última colonia penal insular Islas Marías, México, se estudia solamente su proceso fundacional en 1905 y su justificación jurídica penal para operarla, amparada por la reforma al Código Penal en 1908 en la pena de relegación, que además dio forma al modelo de colonia penal insular. En este constructo, se destaca que las colonias penales insulares latinoamericanas ya no existen en la actualidad. Por lo que, el propósito de la investigación radica en el ofrecimiento de información a las ciencias sociales y humanísticas, para apoyar el conocimiento y construcción del acervo histórico de estas colonias penales insulares que, en su momento, sirvieron al quehacer del penitenciarismo de América Latina.

Por otra parte, es necesario considerar los referentes teóricos de la investigación, que tratan sobre la colonia penal y así, comprender los conceptos claves del tema. Empezando por los aportes de Michel Foucault (1987) en su obra "Vigilar y castigar. Nacimiento de la prisión", con los conceptos de poder, cuerpo y conocimiento. Allí, el autor aborda la normalización de la disciplina de los presos, y así, estudia, describe e interpreta una prisión. Es llamativo que la conclusión de su obra la dirige a la colonia penal de Mettray: “¿Por qué Mettray? Porque es la forma disciplinaria en el estado más intenso, el modelo en que se concentran todas las tecnologías coercitivas del comportamiento. Hay en él, algo «del claustro, de la prisión, del colegio, del regimiento»" (Foucault, 1987, p. 300). Esta conclusión de lo carcelario anota tres principios básicos para la comprensión de una colonia penal: claustro, prisión, colegio y regimiento; formas llevadas a cabo para la normalización disciplinaria de los internos.

Por su parte, Erving Goffman en su obra "Internados. Ensayos sobre la situación social de los enfermos mentales" aporta el concepto de una institución total, que define de la siguiente manera: "como un lugar de residencia y trabajo, donde un gran número de individuos en igual situación, aislados de la sociedad por un periodo apreciable de tiempo, comparten en su encierro una rutina diaria, administrada formalmente" (2001, p. 13). El autor agrega que: "Las cárceles sirven como ejemplo notorio, pero ha de advertirse que el mismo carácter intrínseco de prisión tienen otras instituciones, cuyos miembros no han quebrantado ninguna ley" (2001, p. 13). Goffman clasifica las colonias penales dentro de las instituciones totales.

Hay otras aportaciones teóricas que tratan los asuntos penitenciarios con mucho acierto y destreza, principalmente trabajadas en el campo de las ciencias sociales y humanísticas. Sin embargo, y hasta aquí visto, se pretende por lo menos, dar a comprender el contenido de la problemática del tema que se ha de tratar de las extintas colonias penales insulares en América Latina, específicamente la última de ellas, la Colonia Penal Federal Islas Marías, México, fundada en el año de 1905 y cerrada como tal en el año del 2010, para el cambio a complejo penitenciario.'

Para estos fines se expone el tema con breves recortes históricos del origen del modelo de colonia penal insular que surgió en la Europa de los siglos XVIII y XIX. Después, se aborda cómo estos modelos influenciaron a las nuevas naciones de América Latina de mediados del siglo XIX y comienzos del siglo XX, para crear sus colonias penales insulares. Finalmente, se recorren breves recortes históricos del proceso fundacional y operativo (1905-1908) de la última colonia penal insular de América Latina, la Colonia Penal Federal Islas Marías, en México.

\footnotetext{
1 Se aclara que el Complejo Penitenciario Islas Marías, no fue una colonia penal, sino una prisión basada en métodos alternos al encierro, para atender los requerimientos de la pena de prisión de máxima, media y mínima seguridad. Este complejo penitenciario cerró en el 2019 para el cambio de mandato institucional y dirigido a la conservación y preservación de sus recursos naturales.
} 


\section{MÉTODOS}

Se utilizó un método de enfoque cualitativo y de investigación histórica, para describir e interpretar la construcción del tema objeto de estudio de las extintas colonias penales insulares de América Latina, y en particular, de la última colonia penal insular, la Colonia Penal Federal Islas Marías, en México. Para tal efecto, se recurrió a la recolección de la información mediante fuentes secundarias obtenidas en el siguiente diseño bibliográfico de la investigación:

Bibliografía consultada en el campo de la sociología y relacionada con el movimiento moderno penitenciario en la Europa del siglo XVIII, donde surgió el modelo de la colonia penal como alternativa al modelo de prisión. Así mismo, se consultan teorías del castigo y sociales que tratan los conceptos fundamentales de una colonia penal e institución total, respectivamente.

Bibliografía especializada en el campo de las ciencias penales, donde estudian los primeros códigos penales de las repúblicas en América Latina surgidas en el siglo XVIII, y que amparan y justifican sus primeros modelos de colonias penales insulares en el siglo XIX y principios del siglo XX.

Bibliografía consultada y originada por el proyecto concluido (2012-2017), "Colonia Penal Federal Islas Marías, México (1905-2004) y extinta colonia penal Coiba, Panamá (1912-2004): diferencias y similitudes", que fue apoyado por Ciencia Básicas SEP-CONACYT/165737. Las aportaciones de este proyecto tratan, entre otras, la época histórica de la fundación e inicio de operación de la Colonia Penal Federal Islas Marías, en México.

De esta manera, se establece el proceso de análisis documental, examinando cada uno de los elementos históricos de los que disponen, procurando determinar el grado de confiabilidad de los datos obtenidos y procesados mediante una crítica externa e interna. En la crítica externa, se verifica su autenticidad o validez de la fuente bibliográfica o documento histórico, procurando su forma original y su sentido cronológico de los hechos históricos de las primeras colonias penales surgidas en Europa del siglo XVIII y XIX, y que influenciaron a Latinoamérica en los siglos XIX y XX para la creación de sus propias colonias penales insulares. Mientras que en la crítica interna, se procura la confiabilidad de los datos obtenidos de las fuentes documentales, para la interpretación concreta de los datos históricos en el contenido del presente estudio.

\section{RESULTADOS}

\subsection{Breve historia del origen del modelo de colonia penal insular en Europa de los siglos XVIII y XIX.}

Para estudiar el origen del modelo de colonia penal insular es necesario analizar en breves recortes históricos el inicio del movimiento moderno penitenciario en Europa, que data del siglo XVIII y específicamente en Inglaterra, donde se aportaron dos principios básicos en el ámbito penal: la pena privativa de libertad, que dio origen al modelo de prisión; y la pena de deportación, que dio origen al modelo de colonia penal insular. Por otra parte, la pena de relegación creada en España a mediados del siglo XIX, fue su justificante jurídico para la creación de su modelo de colonia penal insular.

En el inicio de la época del movimiento moderno penitenciario, en la Inglaterra del siglo XVIII, surgió la pena privativa de libertad, donde uno de los precursores fue Cesare Bonnessa, marqués de Beccaria, quien escribió en 1764 su obra cumbre "Tratado de los delitos y las penas", que estableció algunas de sus principales bases y fue impulsor del derecho penal moderno, como la supresión de la pena de muerte y de las torturas.

Otros de los precursores del movimiento moderno penitenciario fue Jeremy Bentham quien, en 1791, entre sus contribuciones creó el concepto del panóptico, que consistía en vigilar todo desde un punto sin ser visto. Dicho concepto fue creado para dar respuesta a los requerimientos de la reciente pena privativa de libertad y dio origen a la forma del modelo de la prisión. Este modelo de prisión se difundió por toda Europa durante el siglo XVIII, llegando, en el siglo XIX, al territorio de lo que hoy es Estados Unidos.

Por su parte, Michel Foucault en su obra "Vigilar y castigar. Nacimiento de la prisión", analiza el modelo de la 
prisión en su diseño del panóptico, como un ejemplo de la nueva tecnología de observación que trascendería al ejército, la educación y las fábricas. En estos términos y referida a la prisión, Foucault afirma que:

Su raíz está en otra parte: en el hecho precisamente de que se pide a la prisión que sea "útil” en el hecho de que la privación de libertad -esa exacción jurídica sobre un bien ideal- ha tenido, desde su comienzo, que ejercer un papel técnico positivo, operar transformaciones sobre los individuos. Y para esta operación el aparato carcelario ha recurrido a tres grandes esquemas: el esquema político-moral del aislamiento individual y de la jerarquía; el modelo económico de la fuerza aplicada a un trabajo obligatorio; el modelo técnico-médico de la curación y de la normalización. La celda, el taller, el hospital. El margen por el cual la prisión excede de la detención está lleno de hecho por unas técnicas de tipo disciplinario. Y este suplemento disciplinario en relación con lo jurídico es, en suma, lo que se ha llamado lo "penitenciario" (1987, p. 251).

Estas aportaciones de Foucault permiten inferir que lo penitenciario son las formas subsecuentes para operar una prisión, transformaciones sobre los individuos por diversas técnicas disciplinarias, cuya combinación técnica y disciplinaria se aplica en tres grandes esquemas: (a) el político y moral de aislamiento individual y de la jerarquía (celdas), (b) el modelo económico de la fuerza aplicada a un trabajo obligatorio (taller), y (c) el modelo técnico y médico de la curación y de la normalización (hospital). Sin embargo, Foucault anuncia pronto el fracaso de una prisión:

Porque inmediatamente la prisión, en su realidad y sus efectos visibles, ha sido denunciada como el gran fracaso de la justicia penal. De una manera muy extraña, la historia del encarcelamiento no obedece a una cronología a lo largo de la cual se asistiera a sucesión sosegada: primeramente, del establecimiento de una penalidad de detención, seguida del registro de su fracaso; después la lenta acumulación de los proyectos de reforma, que darían como resultado la definición más o menos coherente de técnica penitenciaria; luego, la utilización de este proyecto, y finalmente la comprobación de su éxito o de su fracaso. Ha habido de hecho un "telescopaje" o, en todo caso, una distribución distinta de esos elementos. Y como el proyecto de una técnica correctiva ha acompañado el principio de una detención punitiva, la crítica de la prisión y de sus métodos aparece muy pronto, en esos mismos años 1820-1945. (1987, p. 269).

Al respecto, Foucault argumenta que el fracaso de la prisión, estudiada en los años de 1820 a 1945, se debe a las conjeturas que tienen que ver con las altas tasas de reincidencia e indirectamente con la fábrica de delincuentes, entre otras más. Ante estas conjeturas anunciadas por Foucault sobre el fracaso del modelo de prisión al amparo de la pena privativa de libertad, aparece prontamente otra alternativa punitiva: la pena de deportación, que surge también en la Inglaterra del siglo XVIII. Entonces, surge la siguiente pregunta conductora ¿̇con qué fin se crea la pena de deportación? y ¿cómo y dónde se aplica? Sobre estas preguntas arroja luz Concepción Arenal en su libro "Las colonias penales de Australia y la pena de deportación”, así:

Inglaterra, aunque sin un sistema de deportación bien determinado, tenía el propósito y la práctica de deportar sus criminales, y saneaba la atmósfera moral enviándolos a sus colonias de América. El objeto no era más que deshacerse del mayor número con el menor coste posible, y el modo de conducirlos a las Barbadas, a Jamaica y la situación que allí tenían, forman una de las páginas más ignominiosas de que debe avergonzarse un pueblo honrado [...] El gran gasto que primera de estas medidas exigía, y al lado de este motivo, y aun acaso más poderosa que él, la costumbre y la comodidad de enviar a otra parte a los hijos de Inglaterra que no le hacían honor ni le servían de provecho, la determinó a buscar un país remoto, á donde sin obstáculos ni reclamaciones diplomáticas pudiera fundar una colonia penal: ese país fue la Australia. Reconocida muy de paso por Cook y sus compañeros, parecían necesarias nuevas explotaciones para establecer una colonia penal; pero Inglaterra no quería aplazar por más tiempo la evacuación de sus prisiones soladas por el tifus, durante once años de una aglomeración de criminales, para la cual no estaban preparadas, y en diciembre de 1786 se señaló la Nueva Gales del Sur para establecimiento de una colonia penal 
(1895, p. 41-44).

Con lo anterior, la autora deja claro que en la Nueva Gales del Sur (hoy uno de los seis estados que conforman Australia), Inglaterra creo el origen del modelo de colonia penal insular, bajo el justificante jurídico de la pena de deportación y sin un plan concebido, sino más bien, para deshacerse del mayor número de prisioneros que asolaban sus prisiones, principalmente por las aglomeraciones y la propagación de la enfermedad del tifus en esos espacios.

Años más tarde, en la Francia del siglo XIX, se retomó el modelo de colonia penal con la justificación de la pena de deportación, para colonizar sus territorios. Este fue el caso de Argelia, y su creación de colonias penales insulares, como fueron los casos de las islas de la Guayana Francesa y Nueva Caledonia. De aquí que, surge la siguiente pregunta ¿cuál fue el pensamiento político penal de la idea rectora que justifica la pena de deportación para la creación de sus colonias penales? Fernando Cadalso aclara esta pregunta:

Cuando Napoleón era presidente de la república, en su mensaje de 12 de enero de 1850 tomó con calor la colonización, y decía en aquel momento: "seis mil hombres existentes en nuestros penales de Tolón, Brest y Rochefort, gravan el presupuesto de una manera enorme, se corrompen cada día más, y son una amenaza continua a la sociedad; entiendo que la pena de trabajos forzados puede hacerse más eficaz, moralizadora, menos dispendiosa y más humanitaria, utilizando estos penados en pro de la colonización Francesa". Agitábase en Francia desde 1828 la idea de la deportación y de colonizar sus posesiones ultramarinas por penados; y esta corriente, unida a la iniciativa de Napoleón, hizo que en 21 de febrero de 1851 se nombrara una Comisión para estudiar el problema. La Guayana y la Nueva Caledonia, situadas, la primera en la América Central [...] y la segunda en la Melanesia (Oceanía), fueron los puntos en que los comisionados fijaron su atención. (1895, p. 9)

Esta descripción de Fernando Cadalso, sobre la justificación de la pena de deportación aplicada en sus colonias penales insulares francesas, se identifican tres aspectos: el primero, solucionar el hacinamiento de los penales de Tolón, Brest y Rochefort; el segunda, aminorar la carga financiera del presupuesto del gobierno de sus prisiones; y el tercero, una forma de colonizar sus territorios insulares.

En este constructo de la pena de deportación se fraguaba en España del siglo XIX una estrategia para la colonización exterior ultramarina, basada en el movimiento reformador moderno del derecho penal iniciado en el siglo XVIII. Sin embargo, en esa época España continuaba sus prácticas jurídicas penales en la Recopilaciones de las Partidas, el instrumental punitivo heredado del derecho romano. De aquí que, fue hasta mediados del siglo XIX cuando España cristalizó su proyecto de colonización ultramarina creando la pena de relegación al amparo de la reforma de 1850 del Código Penal español de 1848, donde, en el artículo 102, capítulo V “De la ejecución de las penas y de su cumplimiento", Libro Primero, dice que:

Las penas de relegación perpetua y temporal se cumplirán en Ultramar en los puntos que ello destinados por el Gobierno.

Los relegados podrán dedicarse libremente, bajo la vigilancia de la Autoridad, á su profesión ú oficio dentro del radio á que se extiendan los límites del establecimiento penal. (1850, p. 35)

De esta manera, la pena de relegación perpetua y temporal fueron las justificantes jurídicas, al amparo del Código Penal de 1850, para cristalizar el proyecto rector de las colonias penales insulares españolas. Y, de acuerdo con Isabel Ramos, fue el primer proyecto coherente y ordenado de colonización exterior:

De entre todas ellas, la relegación perpetua y la relegación temporal llegarían a describirse, con el tiempo, como las penas previstas para tratar de iniciar en nuestro país un primer proyecto coherente y ordenado de colonización exterior. Pero ante las dificultades de la puesta en marcha de 
tan compleja amalgama de penas, la cuestión no comenzó a dirimirse hasta pasados más de diez años desde la promulgación del Código y la posterior Ley de prisiones de 1849, concretamente en el año 1860, cuando la reina Isabel II respondía a los requerimientos realizados en este sentido por el Ministro de Gobernación especificando que "la pena de relegación perpetua debe cumplirse en las Islas Marianas, y en la de Mindoro la de relegación temporal, cualquiera que sea el grado en que esta se imponga; dejando al prudente arbitrio del Capitán General de Filipinas la facultad de trasladar á los que estén cumpliendo tales condenas á otro punto del distrito de su mando, siempre que lo estime conveniente" (2012, p. 188).

En lo anterior, la autora da a conocer el modelo de colonia penal insular española bajo la justificación jurídica de la pena de relegación perpetua y temporal. Sin embargo, también interesa ¿bajo qué pensamiento jurídico penal se rige la pena de relegación para la creación de sus colonias penales en su proyecto de colonización exterior ultramarina? Al respecto, Isabel Ramos (2013) en otras de sus obras, responde a esta interrogante en tres ideas claves: (1) lo previsto por la ley, (2) la mejor medida para apartar de la sociedad a los delincuentes incorregibles, y (3) para repoblar, mantener y aprovechar los recursos que ofrecían las colonias. De aquí que, se identifican dos aspectos claves: apartar de la sociedad a los delincuentes incorregibles y aprovechar los recursos que ofrecían las colonias penales insulares de su dominio colonial.

Y por último, es importante señalar que el sistema penitenciario aplicado a estas colonias penales insulares españolas, fue la adopción de un régimen progresivo similar al sistema ideado por Crofton. Esto lo afirma Isabel Ramos así:

\begin{abstract}
Adaptándolo al caso español, Francisco Lastres proponía los siguientes: en un primer periodo de entre 6 y 8 meses habría que encerrar al condenado en una penitenciaria celular, siendo los primeros días de incomunicación absoluta y ociosidad, sin permitírsele lectura ni influencia externa alguna. Cumplido el tiempo de aislamiento, los presos deberían pasar a un segundo periodo en el que se dedicasen a trabajos agrícolas o fabriles, conservando el aislamiento por la noche y si exigirles el silencio. Los que, por haber cumplido el segundo periodo de la pena, fueran susceptibles de seguir la libertad, pasarían antes por un aprendizaje que podrían sufrir en las mismas islas señaladas de las Marianas o Guinea, y que "para seguir en todo á Crofton, Ilamaremos a esta prisión intermedia”; y finalmente, el delincuente obtendría la libertad para colocarse y realizar faenas agrícolas o industriales en la colonia, con la supervisión de las autoridades penitenciarias. (2012, p. 191).
\end{abstract}

Lo anterior destaca que el sistema progresivo, adaptado al sistema Crofton, fue aplicado en las primeras colonias penales insulares españolas, dejando en claro una planeación más coherente mediante distintos periodos que habría de pasar el prisionero, desde su ingreso hasta la finalización de su sentencia jurídica y penal, rumbo a su libertad.

Para culminar este apartado, cabe mencionar que el Código Penal Español del siglo XIX tuvo grandes influencias en la creación de los primeros códigos penales de las repúblicas de América Latina, en lo que concernía a la creación de sus colonias penales insulares.

\title{
3.2 Las colonias penales insulares de América Latina de los siglos XIX y XX
}

Las nuevas naciones latinoamericanas, surgidas de la independencia española, se preocuparon y se avocaron a la elaboración de sus propios códigos penales, entendidos estos como el vértice de todo designio jurídico y penal que justificaba su actuación. Pero en sí, y en principio, ¿qué es un código penal? Este concepto jurídico de Código Penal lo define Eugenio Raúl Zaffaroni de la siguiente manera:

Un código, en términos modernos, es un texto legal, es decir, una única ley, que procura abarcar la regulación de toda una rama del saber jurídico. Esta moderna concepción de "código" se vincula al enciclopedismo, que pretendía sintetizar y exponer todo lo concerniente a cada rama del saber humano. Se trata de un texto sistemático, por oposición a los viejos códigos premodernos, que eran 
textos consolidados, como las “recopilaciones” españolas o las “ordenaciones” portuguesas. La idea de código sistemático se fue abriendo paso por efecto de necesidades de gobierno. Cuando se incrementó la centralidad estatal, fueron cada vez más convenientes los códigos sistematizados, para permitir que la voluntad del poder central se realizase en forma pareja en todo el territorio (2000, p. 19).

De este modo, se comprende que el Código Penal preside su sistematicidad y determina los conceptos angulares que permite al poder central aplicar en forma pareja en el país. De aquí que, en estudios realizados de los primeros códigos penales de los países de América Latina, y señalado por la Suprema Corte de Justicia de la Nación de México y el Instituto Latinoamericano de las Naciones Unidas para la Prevención del Delito y Tratamiento del Delincuente, se extrae lo siguiente:

La codificación penal de América Latina presenta un mosaico de elementos ideológicos proveniente de Europa [...]. El fenómeno tampoco es totalmente original de esta región, pues en medida diferente fue conocido en Europa en el siglo XIX, donde los primeros códigos y proyectos no sirvieron como grandes modelos y la codificación se consolidó a partir del código de Napoleón, pues los que luego se sancionaron se guiaron metodológicamente por ese modelo, apartándose o siguiendo su plan y sus soluciones, de modo que cada texto que se apartó del modelo bonapartista en forma ideológicamente coherente devino él mismo un modelo. (2000, p. 22)

Y más adelante agrega:

La particularidad del fenómeno latinoamericano fue que esos modelos casi siempre se importaron, en ocasiones sin comprender su ideología, casi nunca tomando en cuenta la realidad local y, a veces, combinando soluciones de diferentes modelos en forma poco coherente [...] El extraordinario éxito continental de los modelos españoles de 1848, 1850 y 1870, por ejemplo, no obedeció a ninguna identificación ideológica con éstos, sino a que estos textos fueron comentados por muchos autores ilustres. Las combinaciones arbitrarias de soluciones fuera de contexto y las curiosidades suelen ser resultado de las disputas del poder corporativo, de protagonismo político, de eventuales interferencias políticas coyunturales en ámbito legislativo, algunas por mero antojo, como de afanes de notoriedad o de pragmatismo y de urgencia. (2000a, p. 22 y 23)

Por lo tanto, los Códigos Penales de la Europa del siglo XIX (específicamente, los Códigos Penales de España de 1848,1850 y 1870 ) tuvieron su influencia en la construcción de los códigos penales latinoamericanos del siglo XIX y principios del XX, así como en las adecuaciones de la justicia penal latinoamericana. Al respecto, Del Olmo comenta que: "Se había declarado la Independencia de España, pero esa independencia no llegó hasta el campo jurídico. Las leyes seguían siendo fundamentalmente españolas" (1991, p. 133). De aquí que, Del Olmo muestra las influencias de los códigos españoles a los países latinoamericanos, tal como se presenta la tabla 1.

Tabla 1. Primeros códigos penales latinoamericanos

\begin{tabular}{|l|l|l|}
\hline Año & País & Influencia \\
\hline 1826 & El Salvador & Código español 1822 \\
\hline 1830 & Brasil & Código napolitano 1819 y Código Napoleón 1810 \\
\hline 1831 & Perú-Bolivia & Código español 1822 \\
\hline 1835 & Haití & Código Napoleón 1810 \\
\hline 1837 & Nueva Granada & Código Napoleón 1810 y Código español 1822 \\
\hline 1845 & República Dominicana & Código Napoleón 1810 \\
\hline 1863 & Venezuela & Código español 1822 y 1848 \\
\hline
\end{tabular}




\begin{tabular}{|l|l|l|}
\hline 1863 & Perú & Código español 1850 \\
\hline 1865 & $\begin{array}{l}\text { Argentina } \\
\text { (Proyecto Tejedor)* }\end{array}$ & Código Baviera 1813 \\
\hline 1871 & Paraguay & Sigue el Proyecto Tejedor \\
\hline 1871 & México & Código español 1850 \\
\hline 1872 & Cuba & El mismo Código español de 1870 \\
\hline 1872 & Ecuador & Código belga de 1867 \\
\hline 1874 & Chile & Código español de 1850 \\
\hline 1879 & Puerto Rico & El mismo Código español de 1870 \\
\hline 1879 & Nicaragua & Código español 1870 \\
\hline 1880 & Costa Rica & Código español 1870 \\
\hline 1887 & Colombia & Código Napoleón 1810 y Código español 1822 \\
\hline 1889 & Guatemala & Código español 1870 \\
\hline 1889 & Uruguay & Código español 1870 y Proyecto Zanardelli \\
\hline 1898 & Honduras & Código español 1870 \\
\hline
\end{tabular}

*Aunque no se llegó a sancionar, estaba en realidad en vigencia en casi toda la República Argentina hasta que se promulgó el Código en 1886.

Fuente (Del Olmo, 1999, p.134)

De esta manera, se comprende la influencia de los primeros códigos penales de las repúblicas de América Latina, principalmente con los códigos penales españoles de 1822, 1848, 1850 y 1870 . En este constructo y sin precisar bajo qué ley penal se amparan las colonias penales insulares latinoamericanas del siglo XIX y $\mathrm{XX}$, se resumen en orden cronológico su creación y cierre de las mismas:

- Costa Rica crea dos colonias penales insulares: la colonia penal en Isla del Coco, abierta en 1874 y cerrada en 1881, y el presidio en la isla de San lucas, que operó desde 1873 hasta 1977.

- Argentina reabre la Isla Martín García como colonia penal en 1886 y cierra en 1957.

- México crea en 1905 la colonia penal de Islas Marías y la cierra en 2010.

- Panamá crea la colonia penal en Isla de Coiba en 1912 y cierra en 2004.

- Perú crea la colonia penal en isla El Frontón en 1917 y cierra en 1986.

- Cuba reabre la Isla Prisión en Islas de Pinos en 1926 como Presidio Modelo y cierra en 1967

- Brasil crea el Instituto Correccional de la Isla Anchietta en 1942 y cierra en 1955.

- Chile crea la colonia penal en Isla Santa María en 1944 y cierra en 1980.

- Ecuador crea la colonia penal en Isla Isabela en 1946 y cierra en 1959.

- Colombia crea la colonia penal en Isla Gorgona en 1958 y cierra en 1985.

Entre otras históricas colonias penales insulares creadas del siglo XIX y XX en Latinoamérica, interesa mostrar que las únicas que sobrepasaron al siglo XXI fueron las colonias penales de Isla Coiba, Panamá e Islas Marías, México. En este sentido, es de interés estudiar la última colonia penal insular de América Latina: la extinta Colonia Penal Federal Islas Marías, en México.

\subsection{La última colonia penal insular de América Latina: Islas Marías, México}

Islas Marías es un archipiélago integrado por cuatro islas (María Madre, María Cleofás, María Magdalena y San Juanico), situadas en el Océano Pacífico del territorio mexicano. El archipiélago Islas Marías, fue decretado como colonia penal por el entonces presidente de México Porfirio Díaz (1876-1911), el día 12 de mayo de 1905, quien creó en la adición al Código Penal en $1908^{2}$ la pena de relegación, como la justificante

\footnotetext{
2 Refiere al Código Penal para el Distrito Federal y Territorio de la Baja California sobre delitos del fuero común, y para toda la Repú-
} blica sobre delitos contra la Federación, expedido por el Congreso de la Unión, el día 7 de diciembre de 1871. 
jurídica y penal para operarla. De aquí que, se identifican dos principios básicos para comprender su proceso fundacional: primero, se decreta Islas Marías en 1905, como colonia penal y, segundo, la adición al Código Penal en 1908, en la justificación jurídica de la pena de relegación, que le da la forma y el modelo de colonia penal insular para operarla.

Es importante apuntar que el archipiélago Islas Marías ya se fraguaba como colonia penal en el gobierno de Benito Juárez (1858-1872) y el emperador Maximiliano de Habsburgo (1864-1867). Esto lo comenta Barrón Cruz de la siguiente manera:

Tal idea no era nueva: ya se habían realizado diversos esfuerzos para instaurar un sistema penitenciario en ultramar, uno data de la administración presidencial de Benito Juárez quien nombró como responsable de implementar tal idea, al general Manuel Uraga, quién no pudo cumplir la encomienda. Luego el emperador Maximiliano, en 1865, ordenó a través del Ministerio de Justicia el estudio sobre la viabilidad de que los terrenos de las Islas Marías sirvieran para una colonia penal; pero la propuesta no prosperó (2014, p. 45).

Entonces, se comprende la propuesta de Porfirio Díaz (1876-1911) sobre la creación de una colonia penal en Islas Marías. En este marco, destaca en su periodo de gobierno el afán para la creación de una reforma penitenciaria, para la restauración en la administración, procuración e impartición de justicia. Entonces vale preguntarse ¿Cuál fue la idea política-penal de Porfirio Díaz para la creación de la colonia penal en Islas Marías? Siguiendo a Martín Barrón:

La idea básica de la reforma era establecer mayores mecanismos de control y sujeción que permitiera a las élites gobernantes reforzar la idea una paz social, además de contar con una fuerza de trabajo disponible y, fundamentalmente, asegurar las inversiones de capital extranjero en México. Es decir, el orden y progreso, lema de la pax del Porfiriato.

Por lo cual, con Lecumberri se pretendía consolidar dichos objetivos; pero la penitenciaria en sus primeros años de vida no logró los efectos intimidatorios y de control con los que había sido planteada. Así, el islote y la fortaleza de San Juan de Ulúa, siguieron alojando a los reos «incorregibles», que no podían estar en Lecumberri. Por tal motivo en 1902, el general Díaz, instauró la pena de relegación en las Islas María Madre, María Magdalena, María Cleofas y el islote de San Juanito; para hacerlo era necesario la compra de las mismas (2014, p. 46).

Según esto desde 1902 se fraguaba la idea de convertir al archipiélago Islas Marías en una penitenciaria, con la justificación jurídica de la pena de relegación, ya que la obra cumbre del Porfiriato de la penitenciaria Lecumberri (inaugurada el 29 de septiembre de 1900) no cumplió los objetivos de mecanismo de control y sujeción, que permitiera al gobierno reforzar la idea de la paz social. Entonces, se planteó como opción convertir el archipiélago Islas Marías en una penitenciaria, para lo cual, fue necesario su compra. Al respecto, Hernández Sánchez, aclara que existían dos distintos propietarios antes que las adquiriera el gobierno federal de Porfirio Díaz, para convertirlas en colonia penal:

Mayo de 1862. Gral. de Div. José López Uranga, solicita al Supremo Gobierno se le concedan las Islas en propiedad por los servicios prestados a la nación. Y así, El 5 de mayo de 1862 por medio de acta notarial fue declarado propietario de las Islas Marías mediante una donación para él y sus herederos o sucesores.

Julio de 1879. López Uranga vende al señor Manuel Carpena -residente en San Blas, Estado de Jalisco- su propiedad de las Islas Marías el 17 de julio de 1879. Al morir éste, su esposa, Gila Azcona viuda de Carpena, vende las Islas Marías al gobierno federal

Enero de 1905. En enero de 1905 el gobierno federal entra en posesión de las islas y comienza el proyecto de creación de la Colonia Penal. Existe escritura pública emitida por notario el 31 de enero de 1905 en el que la Sra. Gila Azcona Vda. de Carpena vende al gobierno federal las Islas Marías. (2016, p. 63-64). 
De aquí se comprende que, una vez comprado el archipiélago Islas Marías por el gobierno federal, se cristalizó el proyecto de colonia penal, bajo el Decreto publicado en el Diario Oficial el día 12 de mayo de 1905, el cual dicta lo siguiente:

Porfirio Díaz, Presidente Constitucional de los Estados Unidos Mexicanos, á sus habitantes, sabed: Que de conformidad con lo prevenido en el artículo 20 de la ley de 18 de diciembre de 1902, ha tenido á bien decretar lo siguiente:

Artículo único.- Quedan destinadas al establecimiento de una colonia penitenciaria las islas denominadas: María Madre, María Magdalena y María Cleofás, que forman el grupo conocido por las Tres Marías, ubicadas en el Océano Pacífico, frente al territorio de Tepic y que fueron adquiridas por el Gobierno. (1905, sin página)

Ahora bien, decretándose Islas Marías como colonia penal el día 12 de mayo de 1905, también interesa ¿bajo qué pensamiento político de Porfirio Díaz tuvo para la fundación de la colonia penal? Avilés, citando a Madrid y Barrón, comenta lo siguiente:

La colonia penal del Pacífico se creó como una institución de impartición de justicia con carácter intimidatorio, coercitivo y tangible, no sólo para los disidentes políticos, delincuentes comunes, vagos, prostitutas y sujetos identificados como improductivos, sino también como una advertencia perceptible a la sociedad en general. Agregando ellos, que así la política punitiva de exilio, además de reprimir las conductas delictivas dadas a lo largo del territorio nacional en contra del régimen porfirista, tenía la intención de asegurar la posesión de las tres islas, así como la colonización y la explotación de sus riquezas naturales a través del trabajo carcelario (2009, p. 79).

Siguiendo lo anterior, se constata que, en el pensamiento político federal de Porfirio Díaz, destaca principalmente una política punitiva de exilio para aquellos delincuentes en contra del régimen conocido como el Porfiriato.

Ahora bien, respecto al proceso de la fundación de la colonia penal Islas Marías, siguiendo a Martín Barrón, es importante señalar que:

Para el 25 de junio de 1905, una vez finiquitado los trámites de adquisición de las Islas, el Ministro de Gobernación, Manuel Corral, designo a Mariano Ruiz para que en representación del Gobierno Federal tomara posesión de la Islas, e iniciar a los trabajos de acondicionamiento del lugar. Al concluir su misión protocolaria, Ruiz regresó a la Ciudad de México, para informar al Ministro Corral de las condiciones en que había recibido las Islas y entregar su renuncia. Para sustituir a Ruiz se nombró al coronel Abelardo Ávalos, a quien se le encomendó la planeación y distribución de los campamentos, y de los mecanismos de enlace entre las islas y el continente. Pero a los pocos meses de asumir el cargo renunció. En su lugar se nombró a Arturo G. Cubillas, quien efectuó las tareas de acondicionamiento e inauguración del penal del pacífico. Para el 16 de marzo de 1907 arribaron a las Islas los primeros 19 presos que compurgarían su pena. Paulatinamente se enviaron más reos, a quienes se les asignó la labor de abrir brecha en la Isla María, la construcción de las casas para empleados y de las barracas para los presos; así como un hospital, un leprosario y, paradójicamente, una cárcel con rejas. A los colonos “incorregibles” se les asignó el trabajo en las salinas, la idea era reprimir la conducta de desacato a la autoridad que presentaban. (2014, p. 47)

De esta manera se destacan dos fechas importantes en el proceso de fundación de la colonia penal Islas Marías: el 25 de junio de 1905, que data la posesión de las Islas Marías como colonia penal y el 16 de marzo de 1907, cuando arribaron los primeros presos con trabajos como abrir brechas y construir casas para empleados, barracas para los presos, un hospital, leprosario y una cárcel. Asimismo, se destaca el papel del 
director de la colonia penal, Arturo G. Cubillas - quien, retomando a Evangelina Avilés (2013), dirigió entre 1906 y 1910- a quien correspondía el acondicionamiento e inauguración de la colonia penal.

Ahora bien, dentro de las reformas penales para este tipo de institución penal y encaminada a la pena de relegación, Héctor Madrid comenta que:

En cuanto a la pena de transportación o relegación, la Comisión elaboró un capítulo especial, el cual fue dado a conocer al Ejecutivo a finales del mes de marzo de 1906; examinado por un cuerpo de Ministros, quienes al aprobarlo en lo general y en lo particular, sólo modificaron el tiempo que deberían permanecer los reos remitidos en la colonia penal de un año a dos.

Por su parte, la Secretaria de Gobernación consideró que dicha propuesta estaba íntimamente ligada con la preparación para la reorganización de los sistemas penales del Distrito Federal y para la creación de la colonia penal, por lo que remitió ambos proyectos a la Secretaría de Justicia el 20 de noviembre de 1907, solicitando su opinión; y si los consideraba viables, se sirviera dirigirlos al Congreso de la Unión.

Así, el 7 de marzo de 1908, la Secretaría de Justicia transcribió a la Comisión el oficio de Gobernación, remitiéndoles una copia de los proyectos. En un lapso relativamente corto, la Comisión respondió (22 de abril) que estaba de acuerdo. La Comisión dictaminadora, por su parte, introdujo en el proyecto algunos cambios al formular su dictamen en el transcurso del debate y conclusión del mismo, y así se creó la nueva ley sobre la pena de relegación, la cual dio origen a la vida estatutaria de la Colonia Penal, Islas Marías (2016, p. 13-14).

De este modo, se cristaliza la pena de relegación en la adición al Código Penal para el Distrito y Territorios Federales sobre delitos del fuero común, y para toda la República, contra delitos a la federación, publicado en el Diario Oficial el día 20 de junio de 1908, en el cual se transcriben los siguientes artículos:

Artículo $1^{\circ}$ Se establece la pena de relegación, la cual se hará efectiva en colonias penales establecidas en islas ó en lugares que sean de difícil comunicación con el resto del país.

Artículo $2^{\circ}$ La pena de relegación tendrá dos períodos:

El primero será de prisión celular, con incomunicación parcial y con trabajo.

El segundo será también de prisión, pero con trabajo en común, dentro ó fuera de la cárcel bajo custodia inmediata. Durante la noche, los reos estarán incomunicados entre sí, ó, por lo menos divididos en grupos no mayores de diez, en cada aposento.

Artículo $3^{\circ} \mathrm{El}$ primer período durará un noveno de la condena; pero si dicho noveno excediera de tres meses, ésta será la duración del período, salvo lo dispuesto en los dos artículos siguientes.

El segundo período durará el tiempo necesario para que unido al que conforme á la primera parte de este artículo, se hubiere fijado para el primero, iguale al cuarto de la condena; pero sin que pueda bajar de un mes ni exceder de seis; salvo lo dispuesto en los dos artículos siguientes:

Artículo $4^{\circ}$ Todo reo, al ser recibido en la Colonia, será destinado al primer período, y sólo que observare buena conducta en los términos que prevenga el reglamento interior, pasará al segundo, y de ésta á la libertad preparatoria.

Artículo $5^{\circ}$ Los reos que cometieren nuevos delitos ó faltas, aun cuando sólo sean disciplinarias, serán castigados en los términos que fije el reglamento de la Colonia, volviéndoseles al período anterior, ó aumentándoseles el tiempo que hayan de permanecer en el período en que se encuentren, sin perjuicio de que se les aplique la pena de nuevo delito ó falta.

Artículo $6^{\circ}$ Respecto del producto del trabajo, y, en general, en los demás puntos no determinados en este decreto, regirán para la pena de relegación las mismas reglas que para la de prisión.

Artículo $7^{\circ}$ Los reos condenados á relegación á quienes se conceda la libertad preparatoria, deberán residir todo el tiempo de ésta en la Colonia Penal.

Artículo $8^{\circ}$ La pena de relegación se entiende impuesta con calidad de retención por una mitad más de tiempo, y así se expresará en la sentencia, para el caso de que el reo tenga mala conducta durante la segunda mitad de su condena, cometiendo algún delito, resistiéndose á trabajar ó incurriendo en faltas graves de disciplina, ó en graves infracciones de los reglamentos.

Los reos que salgan de la Colonia serán trasladados por cuenta de la administración pública al lugar en que residían antes de ser aprendidos. 
Artículo $9^{\circ}$ En las colonias penales se permitirá que continúen residiendo los reos que hayan extinguido sus condenas, y que se establezcan en ellas las familias de los mismos y otras personas libres, todo en los términos que dispongan los reglamentos.

Artículo 10. La pena de relegación se aplicará en substitución de la de arresto mayor y de las de reclusión en establecimiento de corrección penal ó prisión que no exceda de dos años:

I. Cuando la condena sea por robo, vagancia, mendicidad ó fabricación ó circulación de moneda falsa;

II. Cuando el reo sea reincidente ó cuanto de las constancias del proceso aparezca que es delincuente habitual y que hay motivo fundado para creer que para se enmienda, es necesario que cambio de medio y de género de vida.

Artículo 11. La substitución de las penas de arresto, reclusión ó prisión, por la de relegación, se hará computándose á razón de dos días de ésta por cada uno de aquellas. Si del cómputo resultare un término inferior á seis meses, se aplicará, sin embargo, la relegación por todo ese tiempo (1908, p. 573-574).

De esta manera, se comprende la justificación jurídica de la pena de relegación, que da forma al modelo de colonia penal para su operación, en la que se identifica la adaptación del proceso sistémico progresivo, similar al caso español para el tratamiento penitenciario de los presos. Esto, basado en la evolución o involución de la conducta de estos, reflejado en sus dos periodos (prisión celular con incomunicación parcial y con trabajo; y prisión, pero con trabajo en común, respectivamente), y luego, a la libertad preparatoria y extinción de su condena. Asimismo, destaca que a aquellos reos que hayan extinguido sus condenas se les permitirá continuar residiendo en la colonia penal y que se establezcan en ellas las familias de estos, incluyendo a otras personas libres.

Ahora bien, para una mayor comprensión de los artículos de la adición al Código Penal en la aplicación de la pena de relegación, se anota la circular expedida el 29 de junio de 1908, sobre la reorganización de la colonia penal Islas Marías, expedida por el Secretario de Estado y del despacho de Gobernación, Ramón Corral; así como el comienzo de la vida en la colonia penal en la aplicación administrativa de la pena de relegación desde el ingreso y egreso de los reos. Esto lo comenta siguiendo a Hernández Sánchez, en lo siguiente:

A la llegada de cada reo, se le abrirá en el libro que habrá de llamarse registro general, su correspondiente partida, en la cual se hará constar:

(...)

El día último de cada mes se anotará a cada uno de los reos existentes en la colonia, en sus respectivas partidas del registro general, la conducta que durante el mes hubieren observado y, caso de que se hubieren resistido a trabajar o hubieren cometido otra falta disciplinaria o algún delito, así se expresará en la correspondiente anotación especificando la falta o el delito cometido.

De conformidad con lo establecido en el artículo cuarto del decreto que adicionó el Código Penal, toda persona privada de su libertad, al ser recibida en la colonia, debía destinarse al primer periodo, que será de prisión celular con incomunicación parcial, esto es, incomunicación con las demás personas que se encuentran ahí, y con trabajo.

Los reos que, estando en el segundo período, se resistieren a trabajar, cometieren alguna otra falta grave, a juicio del director de la colonia, o cometieren algún delito, serán retrocedidos al primer periodo, en el que de nuevo habrán de permanecer el tiempo fijado en el párrafo anterior.

Los reos que hayan permanecido ya en el segundo periodo el tiempo que como mínimum les corresponda y hayan observado, durante él, buena conducta, serán puestos por la dirección en libertad preparatoria, debiendo residir en la colonia penal todo el tiempo que les falta para extinguir su condena.

Durante ese tiempo gozarán de libertad, sin más restricciones que las que sean indispensables para el buen orden y la disciplina de la colonia en términos que fijan los respectivos reglamentos o acuerdos; pero, si observaren mala conducta, volverán a ser colocados en el segundo período o aún en el primero, según la gravedad de la falta que cometieren. Los que cometieren algún delito serán retrocedidos precisamente al primer período.

$\mathrm{Si}$ al concluir el término de la pena, no se hubiere comunicado a la dirección el fallo relativo a la retención del reo, éste será puesto inmediatamente en libertad, si no estuviere encausado por otro 
delito, ni debiera extinguir otra pena, dándose aviso a la Secretaría de Gobernación.

Los reos que, conforme las reglas precedentes, deban salir de la colonia penal, serán remitidos al puerto de san Blas en el primer viaje que se haga ha dicho puerto.

Al salir de la colonia, se les entregará por el director un salvoconducto, en el que se hará constar que han extinguido su condena y, en su caso, la correspondiente retención y aviso que han sido puestos en libertad.

(...)

Los reos que, después de extinguir su condena y la retención, en su caso, quisieran permanecer en la colonia, podrán hacerlo, sujetándose a los reglamentos y acuerdos respectivos (2016, p. 69-70).

De lo anterior, se comprende de manera explícita la forma administrativa del tratamiento penitenciario de los presos de la colonia penal, desde su llegada hasta obtener su libertad; o, en su caso, una vez obtenida su libertad si desean seguir permaneciendo en el lugar y su sujeción a la normatividad respectiva. Asimismo, se da cuenta de que el tratamiento penitenciario va encausado a la normalización de conducta de los presos. Esto, de alguna u otra forma, se asemeja a lo dicho por Foucault sobre la normalización de la disciplina, en la que se derivan los conceptos poder, cuerpo y conocimiento. De tal manera que:

La disciplina en el momento histórico en que nace el arte del cuerpo humano, que no tiende únicamente al aumento de sus habilidades, ni tampoco a hacer más pesada su sujeción, sino a la formación de un vínculo que, en el mismo mecanismo, lo hace tanto más obediente cuanto más útil, y al revés. Formase entonces una política de las coerciones que constituyen un trabajo sobre el cuerpo, una manipulación calculada de sus elementos, de sus gestos, de su comportamiento. (1987, p. 141)

Agrega Foucault, que el cuerpo humano entra en un mecanismo de poder que lo explora, desarticula y la recompone. Una "anatomía política", que es igualmente una "mecánica del poder". Asimismo, el poder y los cuerpos se encuentran atrapados en el tercer elemento, a lo que Foucault Ilama "conocimiento". El conocimiento para Foucault, lo infiere a las técnicas y estrategias implementadas para el tratamiento penitenciario. Así pues, se comprende que estos tres conceptos se dirigen al objetivo de la normalización disciplinaria de los presos.

Ahora bien, en el seguimiento de este proceso histórico de la fundación y operación de la colonia penal Islas Marías, es Arturo G. Cubillas (1906-1910) como director de la colonia penal, a quien le corresponde esta nueva adaptación enunciada en la pena de relegación, con un reglamento provisional para operarla. De la investigación realizada se desconoce el contenido y existencia de este reglamento provisional para ponerla en marcha, ya que su primer Reglamento Interno oficial, se expidió el 10 de marzo de 1920. Por lo tanto, se recurrió en parte a la identificación de la estructura administrativa del director Cubillas, mediante la planta de empleados que se muestra en la tabla 2.

Tabla 2. Planta de empleados de las Islas Marías

\begin{tabular}{|l|l|l|l|}
\hline \multicolumn{4}{|c|}{ Planta de empleados de la colonia penal Islas Marías 1907-1910 } \\
\hline $\begin{array}{c}\text { Número de } \\
\text { plaza }\end{array}$ & \multicolumn{1}{|c|}{ Nombre de la plaza } & \multicolumn{1}{|c|}{ Cuota diaria } & \multicolumn{1}{|c|}{ Cargo } \\
\hline 1 & Director General & $\$ 13.15$ & Gobernación \\
\hline 1 & Subdirector & $\$ 10.00$ & Dirección \\
\hline 1 & Escribante & $\$ 1.70$ & Dirección \\
\hline 1 & Contador & $\$ 10.00$ & Administrativo \\
\hline 1 & Auxiliar Contable & $\$ 4.00$ & Administrativo \\
\hline 1 & Proveedor & $\$ 4.20$ & Administrativo \\
\hline 1 & Mayordomo General & $\$ 4.00$ & Administrativo \\
\hline 5 & Mayordomos & $\$ 2.50$ & Administrativo \\
\hline 4 & Capataces & $\$ 2.00$ & Administrativo \\
\hline
\end{tabular}




\begin{tabular}{|c|c|c|c|}
\hline 1 & Jefe Celadores & $\$ 3.35$ & Seguridad \\
\hline 9 & Celadores & $\$ 2.00$ & Seguridad \\
\hline 1 & Doctor & $\$ 8.00$ & Servicio Médico \\
\hline 1 & Farmacéutico & $\$ 4.00$ & Servicio Médico \\
\hline 2 & Ayudantes & $\$ 0.50$ & Servicio Médico \\
\hline 2 & Enfermeras & $\$ 0.50$ & Servicio Médico \\
\hline 1 & Mozo & $\$ 1.00$ & Servicio Médico \\
\hline 1 & Profesor de Instrucción & $\$ 3.35$ & Servicio General \\
\hline 1 & Profesor de Instrucción & $\$ 2.35$ & Servicio General \\
\hline 1 & Profesor de Música & $\$ 4.00$ & Servicio General \\
\hline 1 & Mecánico Herrero & $\$ 4.00$ & Servicio General \\
\hline 1 & Mecánico Auxiliar & $\$ 4.00$ & Servicio General \\
\hline 1 & Jefe Carpintero & $\$ 4.00$ & Servicio General \\
\hline 1 & Vaquero & $\$ 2.20$ & Servicio General \\
\hline 1 & Patrón & $\$ 2.75$ & Servicio General \\
\hline 4 & Bogas & $\$ 1-50$ & Servicio General \\
\hline 1 & Mozo & $\$ 1.50$ & Servicio General \\
\hline 1 & Encargado de Destilación & $\$ 5.00$ & Servicio General \\
\hline 1 & Ayudante & $\$ 1.65$ & Servicio General \\
\hline 3 & Ayudante & $\$ 1.00$ & Servicio General \\
\hline 2 & Maquinistas & $\$ 1.50$ & Servicio General \\
\hline 2 & Aceitadores & $\$ 1.00$ & Servicio General \\
\hline 2 & Fogoneros & $\$ 1.00$ & Servicio General \\
\hline 2 & Cebadores & $\$ 1.00$ & Servicio General \\
\hline \multirow[t]{2}{*}{1} & Cocinero Director & & \\
\hline & Juez de Paz & & \\
\hline 1 & Secretario del Juez & & \\
\hline 1 & Comandante & & \\
\hline 50 & Soldados de Tropa & & \\
\hline
\end{tabular}

Fuente: Madrid Mulia, 2016, p. 27-28.

En el cuadro 2 se podrá notar la identificación de la estructura y forma de organización penitenciaria de Islas Marías, en donde se destaca lo siguiente: Dirección general, Subdirección, Administración, Servicios generales y Seguridad. Asimismo, se destaca la figura de un juez de paz, comandante y soldados de tropa. En estudios realizados, el juez de paz infería en los asuntos civiles (actas de nacimiento, matrimonio y defunciones) y penales no graves; por su parte, los cargos del comandante y soldados de tropa, responden a la necesidad planteada desde los inicios de la fundación de la colonia penal de presencia de fuerza militar de guerra y marina, para coadyuvar a la seguridad, vigilancia y custodia del archipiélago Islas Marías, así como la seguridad, vigilancia y custodia de la colonia penal asentada en la Isla María Madre.

Sumado a lo anterior, Avilés (2009 y 2013) data que estos cargos y funciones de la estructura funcional de los comienzos operativos de la colonia penal, se desarrollaban en dos espacios denominados "campamentos": el primero de ellos, fue el campamento Balleto y el segundo, el campamento Salinas. Asimismo, por el tipo y formas de actividades realizadas en los campamentos, de quienes estaban en tratamiento penitenciario (los colonos y colonas) ${ }^{3}$ y quienes la ejercían, operaban y dirigían (el cuerpo administrativo, servicios generales y seguridad), y que se caracterizaban en relaciones cara a cara. De aquí que, el campamento de la colonia penal adquirió la característica de una institución total, similar a lo dicho por Erving Goffman, quien dicta lo siguiente:

\footnotetext{
3 Factor cultural en la denominación de presos y presas de la colonia penal.
} 
La característica central de las instituciones totales puede describirse como una ruptura de las barreras que separan de ordinario estos tres ámbitos de la vida. Primero, todos los aspectos de la vida se desarrollan en el mismo lugar y bajo la misma autoridad única. Segundo, cada etapa de la actividad diaria del miembro se lleva a cabo en la compañía inmediata de un gran número de otros, a quienes se da el mismo trato y de quienes se requiere que hagan juntos las mismas cosas. Tercero, todas las etapas de las actividades diarias están estrictamente programadas, de modo que una actividad conduce en momento prefijado a la siguiente, y toda la secuencia de actividades se impone desde arriba, mediante un sistema de normas formales explícitas, y un cuerpo de funcionarios. Finalmente, las diversas actividades obligatorias se integran en un solo plan racional, deliberadamente concebido para el logro de los objetivos propios de la institución (2001, p.19-20).

Lo anterior, comprende que dentro las características claves de una institución total, está el desarrollo de las distintas actividades en compañía de otros y bajo una autoridad única y en el mismo lugar, apoyadas por un cuerpo de funcionarios en la encomienda de ejercer y dirigir las actividades diarias estrictamente programadas. Esto, mediante las normas formales para llevar a cabo el cumplimiento de los objetivos de la institución. De esta manera y hasta lo aquí visto, la colonia penal Islas Marías cumple las características que la identifican como una institución total. Sin embargo, hay otro aspecto clave de las instituciones totales y se refiere a la supervisión de un personal, cuya actividad específica no es la orientación ni la inspección periódica, sino más bien la vigilancia. Al respecto Erving Godwam dice lo siguiente:

Ver que todos hagan lo que se les ha dicho claramente que se exige de ellos, en condiciones en que la infracción de un individuo probamente se destacaría en singular relieve contra el fondo de sometimiento general, visible y comprobado. Aquí no se juega la preeminencia entre el gran conglomerado humano y el reducido personal supervisor; están hecho el uno para el otro (2001, p. 20).

Se comprende pues, que la vigilancia tiene una misión específica en una institución total, en el manejo de un grupo reducido de empleados, a quien se le denomina supervisor. Mientras que, los supervisados, Erving Goffman los denomina internos.

Para finalizar, y retomando el proceso histórico de la fundación y operación de la colonia penal Islas Marías, se muestran los ingresos de presos y presas desde 1906 hasta 1913, en la tabla 3:

Tabla 3. Ingreso de presos y presas 1906-1913 de la Colonia Penal Islas Marías

\begin{tabular}{|l|l|l|l|}
\hline Años & Hombres & Mujeres & Total \\
\hline $1906-1907$ & 105 & & 105 \\
\hline $1907-1908$ & 412 & 77 & 489 \\
\hline $1908-1909$ & 1661 & 220 & 1881 \\
\hline $1910-1911$ & 2041 & 299 & 2340 \\
\hline $1911-1912$ & 1245 & 198 & 1443 \\
\hline $1912-1913$ & 31 & & 31 \\
\hline TOTAL & 5495 & 794 & 6289 \\
\hline
\end{tabular}

Fuente: Barrón Cruz, 2014, p. 50

Nótese en los datos que el ingreso de mujeres reclusas a la colonia penal inicia desde 1907, mientras que los hombres reclusos ingresan a la colonia penal desde 1906. Asimismo, se podrá notar el incremento de presos y presas entre 1910 y 1912, y posteriormente una disminución de presos en 1912 y 1913; esto último, fue consecuencia del movimiento de la Revolución Mexicana, que inició en 1910 y culminó en 1917. Una 
vez culminada la revolución, se creó una nueva Constitución Política, publicada en el Diario Oficial de la Federación el 5 de febrero de 1917, con nuevos ordenamientos sociales, políticos y económicos. Además, se creó el primer Reglamento Interno de la colonia penal, expedida el 10 de marzo de 1920, conservando los mismos patrones jurídicos de la pena de relegación.

Así, y en la medida que se fueron complejizando las adaptaciones legislativas de la nueva Constitución Mexicana en 1917, las funciones operativas de la colonia penal mantenían su curso en la pena de relegación y se regularizaron sus funciones administrativas con la creación del primer Estatuto de Islas Marías, publicado en el Diario Oficial de la Federación el 30 de diciembre de 1939, el mismo que dio vida estatutaria a la Colonia Penal Federal Islas Marías.

\section{CONCLUSIONES}

Las extintas colonias penales insulares de América Latina presentan distintas formas en su justificación jurídica y penal para crearlas, mediante sus respectivos códigos penales, reconociéndose la influencia principalmente de los códigos penales de la España del siglo XIX. En cuanto a lo que corresponde a la fundación de la colonia penal Islas Marías, en México, es también parte de los resultados de las influencias del Código Penal de España de 1850 y 1870, con la pena de relegación.

Sin embargo, unas de las atribuciones que destaca la fundación y operación en la pena de relegación de la colonia penal Islas Marías, con respecto a los referentes teóricos de Foucault en los conceptos poder, cuerpo y conocimiento (conceptos dirigidos a la normalización de la disciplina de los internos), fue su despliegue en la integración y forma de la organización penitenciaria en su momento histórico analizado de Islas Marías. Esto fue, la integración de tres principios básicos que la estructuraron: lo penal, lo social y, lo público.

En lo penal, figuran los procedimientos técnicos y penales para el tratamiento penitenciario de los presos y presas, adaptados del sistema penitenciario progresivo (técnica utilizada para la normalización disciplinaria de los presos) y llevado a cabo con las funciones de la estructura administrativa, servicios generales y seguridad. Mientras que en lo social, la presencia de las instituciones sociales identificadas, tales como: familia, educación, trabajo, salud, cultura, militar y cárcel, las mismas que coadyuvaron al tratamiento penitenciario en Islas Marías. Y por último, la instancia pública identificada como el Juez de Paz, para los asuntos de dar Fe, por medio de registros de nacimientos de hijos, matrimonios y defunciones.

De esta manera, los tres principios básicos (lo penal, lo social y lo público) que estructuraron las formas de la organización penitenciaria de los espacios de Islas Marías, se reflejan en las características de una institución total y de tipo comunitario, esto, mediante la presencia de instituciones sociales participantes, tales como: familia, trabajo, educación, cultura, entre otros. Estas últimas, coadyuvaron al tratamiento penitenciario de los colonos, lo que lo convierte en un caso sui géneris de las extintas colonias penales insulares de América Latina.

Así, la Colonia Penal Federal Islas Marías, en su trayectoria de sus 105 años de funcionamiento, fue evolucionando con nuevas reformas jurídicas y penales, tanto en el Artículo 18 Constitucional (regeneración, readaptación social y reinserción social); como en las adiciones al Código Penal (la pena de prisión deroga la pena de relegación); en el tratamiento penitenciario (progresivo y progresivo técnico); y en la creación de la Ley que Establece las Normas Mínimas sobre la Readaptación Social del Sentenciado en 1971. De esta manera, se creó el segundo y último Reglamento Interno de Islas Marías en 1991, que deroga al primer Reglamento Interno de 1920. Asimismo, se anota que el archipiélago Islas Marías fue declarado Área Natural Protegida y Reserva de la Biosfera en el año 2000, continuando con las funciones propias de la colonia penal.

Para finalizar, el resultado de la investigación del periodo de la fundación, que operaba bajo el amparo de la pena de relegación, permite indicar que sus elementos culturales de inicio, si bien no persistieron con las características originales, aún subsistieron en sus formas de organización penitenciaria de sus espacios tipo comunitario y denominados campamentos, donde transcurrió el tratamiento penitenciario de los internos e internas. Estos fueron modificados, acumulados y evolucionaron en 11 campamentos antes de su cierre en el 2010. 
Como último comentario, es necesario anotar que el cierre de Islas Marías como colonia penal en 2010, fue para cambiar al modelo de complejo penitenciario. Este complejo penitenciario cerró finalmente en el año 2019, para darle un giro hacia la conservación y preservación de la Reserva de la Biosfera Islas Marías, cuyo cargo le corresponde a la Secretaría del Medio Ambiente y Recursos Naturales. Por lo tanto, queda abierta una tarea para futuras investigaciones en la construcción de la historia en las distintas épocas durante los 114 años de Islas Marías, que funcionó como colonia penal (1905-2010) y como complejo penitenciario (2010-2019)4. Así también, queda pendiente apoyar el presente y futuro de la Reserva de la Biosfera Islas Marías, en sus nuevos proyectos a cargo de la Secretaría del Medio Ambiente y Recursos Naturales.

\section{REFERENCIAS}

Arenal, C. (1895). Las colonias penales de la Australia y la pena de deportacion. Carlos III University of Madrid.

Avilés Quevedo, E. (2013). El espacio comunitario de Islas Marías. Usos e implicaciones en la reinserción social, 1905-2008. UAS y Del Lirio

Avilés Quevedo, E. (2009). Arquitectura y urbanismo de Islas Marías. Una práctica del diseño en la readaptación social. Editorial UAS y Del Lirio.

Barrón Cruz, M.G. (2014). Islas Marías. Espacio penitenciario de una historia por construir. En Avilés \& Barrón (Coords.) Modelos y espacios de reinserción social, (pp. 41-79). INACIPE y UAS.

Beccaria, C. (1764). Tratados de los delitos y de las penas. Carlos III University of Madrid.

Cadalso, F. (1895). La pena de deportación. La colonización por penados. Universidad de Sevilla.

Código penal de España. Edición oficial reformada 1850. En la imprenta nacional. http://fama2.us.es/fde/codigoPenali848. $p d f$

Decreto adicionando el Código Penal para el Distrito y Territorios Federales, sobre delitos del Fuero común, y para toda la República, sobre delitos contra la Federación. Número 430. Diario Oficial, México, junio 20 de 1908. Disponible en: http://cdigital.dgb.uanl.mx/la/1080046951_C/1080046918_T84/1080046918_110.pdf.

Decreto por el que se desincorporan del Sistema Federal Penitenciario los Centros Federales de Readaptación Social que se indican, ubicados en el Complejo Penitenciario Islas Marías. Diario Oficial de la Federación, México, 8 de marzo de 2019. Disponible en: https://dof.gob.mx/nota_detalle.php?codigo=5552278\&fecha=08/03/2019.

Del Olmo, R. (1999). América Latina y su criminología (Cuarta edición). Siglo Veintiuno Editores.

Foucault, M. (1987). Vigilar y Castigar. Nacimiento de la prisión (Decimosegunda edición en español). Siglo XXI

Goffman, E. (2001). Internados: ensayos sobre la situación social de los enfermos mentales ( $1^{\mathrm{a}}$. Ed. $3^{\mathrm{a}}$ reimp.). Amorrortu.

Hernández Sánchez, J.L. (2016). Evolución del régimen jurídico de las Islas Marías. De colonia penal a complejo penitenciario. En Avilés \& Barrón (Coords.) Islas Marías. De colonia penal a complejo penitenciario, (pp. 53-121). INACIPE y UAS.

Madrid Mulia, H. y Barrón Cruz, M.G. (2000). Islas Marías. Una visión iconográfica. INACIPE.

Madrid Mulia, H. (2016). La relegación penal en México: Islas Marías un espacio punitivo. En Avilés \& Barrón (Coords.) Islas Marías. De colonia penal a complejo penitenciario, (pp. 1-52). INACIPE y UAS.

Ramos Vázquez, I. (2012). La colonización exterior penitenciaria en España: proyectos y realidades, GLOSSAE. European Journal of legal History, (9), 171-202. https://cutt.ly/shJ7461

Ramos Vázquez, I. (2013). La reforma penitenciaria en la historia contemporánea española. Dykinson.

Suprema Corte de Justicia de la Nación de México (2000). Códigos penales de los países de América Latina. Suprema Corte de Justicia de la Nación.

Zaffaroni, E.R. (2000). Introducción. Los códigos penales de Latinoamérica. En Suprema Corte de Justicia de la Nación, Códigos penales de los países de América Latina, (pp. 15-20). Suprema Corte de Justicia de la Nación.

\footnotetext{
4 Para el apoyo y construcción historiográfico de Islas Marías en sus 114 años de funcionamiento como penitenciaria se sugiere revisar a Madrid y Barrón (2002), Avilés y Barrón (2014 y 2016), Avilés (2009 y 2013), así como nuevas aportaciones de Pulido (2018).
} 


\section{AUTORA}

Evangelina Avilés. Doctora en Ciencias Sociales, Maestra en Arquitectura y Urbanismo y Licenciada en Arquitectura. Profesora e investigadora de la Facultad de Arquitectura de la Universidad Autónoma de Sinaloa. Área de investigación diseño urbano-arquitectónico y reinserción social. Miembro del Sistema Nacional de Investigadores nivel 1 por el CONACYT y miembro honorifico del Sistema Sinaloense de Investigadores y Tecnólogos por el INAPI-SINALOA

\section{Conflicto de intereses}

La autora informa ningún conflicto de interés posible.

\section{Financiamiento}

No existió asistencia financiera de partes externas al presente artículo.

\section{Agradecimientos}

Al Consejo Nacional de Ciencia y Tecnología (CONACYT), por el apoyo al proyecto de investigación "CoIonia Penal Federal Islas Marías, México (1905-2004) y extinta colonia penal Coiba, Panamá (1912-2004): diferencias y similitudes" CB SEP-CONACYT 2011-1/165737, durante los años 2012 al 2017. Y, al Programa de Fortalecimiento y Apoyo a Proyectos de Investigación (PROFAPI) de la Universidad Autónoma de Sinaloa, por los apoyos financieros otorgados a las proyectos de investigación realizado en la Colonia Penal Federal Islas Marías, durante el tiempo comprendido de 2006 al 2015.

\section{Sobre el artículo}

El artículo es producto de investigaciones realizadas del proyecto "Colonia Penal Federal Islas Marías, México (1905-2004) y extinta colonia penal Coiba, Panamá (1912-2004): diferencias y similitudes”, apoyado Ciencias Básicas SEP-CONACYT 2011-1/165737, durante los años 2012 al 2017 